Check for updates

Cite this: RSC Adv., 2018, 8, 22469

Received 13th April 2018

Accepted 12th June 2018

DOI: $10.1039 / c 8 r a 03166 e$

rsc.li/rsc-advances

\section{Dopamine incorporating forward osmosis membranes with enhanced selectivity and antifouling properties $\dagger$}

\author{
Yi Wang, ${ }^{\text {ab }}$ Zhendong Fang, ${ }^{\text {a }}$ Shuaifei Zhao, (D) *c Derrick Ng, ${ }^{b}$ Juan Zhang $^{\mathrm{d}}$ \\ and Zongli Xie (DD *b
}

A new type of polyamide thin-film composite forward osmosis (FO) membranes were prepared by controlling dopamine self-polymerization in the aqueous phase during interfacial polymerization. The as-prepared membranes were investigated by attenuated total reflection Fourier transform infrared, $\mathrm{X}$ ray photoelectron spectroscopy, field-emission scanning electron microscopy, atomic force microscopy and water contact angle measurements. The influence of the dopamine self-polymerization degree with different polydopamine particle sizes on membrane morphologies and chemical properties was studied by regulating dopamine concentrations in the aqueous phase. FO performance of the membrane was evaluated under two different modes, i.e. active layer facing draw solution (AL-DS) and active layer facing feed solution (AL-FS). The optimized FO membranes achieved a doubly enhanced water flux $(22.08 \mathrm{~L}$ $\mathrm{m}^{-2} \mathrm{~h}^{-1}$ ) compared with the control membrane without dopamine incorporation, and a half-reduced reverse salt flux ( $32.77 \mathrm{mmol} \mathrm{m} \mathrm{m}^{-2} \mathrm{~h}^{-1}$ ) with deionized water as the feed and $1 \mathrm{M} \mathrm{NaCl}$ as the draw in the AL-FS mode. The optimized FO membrane showed a significantly reduced structural parameter (176 $\mu \mathrm{m})$ compared with the control membrane $(635 \mu \mathrm{m})$, indicating the minimised internal concentration polarization. Moreover, the new FO membranes had less flux decline than the control membrane, suggesting the improved antifouling performance of the membrane. Incorporation of dopamine during interfacial polymerization can be an effective strategy to fabricate high-performance FO membranes with excellent antifouling properties.

\section{Introduction}

Nowadays, water shortage and the energy crisis are two huge challenges for many communities around the world due to the exponentially growing population and the depletion of fossil fuels. ${ }^{1,2}$ Forward osmosis (FO) has attracted increasing interest in desalination, ${ }^{3-5}$ wastewater treatment, ${ }^{6,7}$ osmotic membrane bioreactor, ${ }^{8,9}$ fertilizing ${ }^{10,11}$ and power generation. ${ }^{12,13}$ It is an alternative to reverse osmosis (RO) as a low-cost and more environmentally friendly technology addressing the two issues. ${ }^{14}$ Thin-film composite polyamide (TFC-PA) membranes consisting of an active layer and porous substrate layer have been widely investigated for FO due to their excellent separation

${ }^{a}$ Water Industry and Environment Engineering Technology Research Centre, 401311, Chongqing, China

${ }^{b}$ CSIRO Manufacturing, Clayton, VIC 3168, Australia. E-mail: zongli.xie@csiro.au; Tel: $+61-3-95452938$

'Department of Environmental Sciences, Macquarie University, Sydney, NSW 2109, Australia. E-mail: shuaifei.zhao@mq.edu.au; Tel: +61-2-98509672

${ }^{d}$ Institute for Frontier Materials, Deakin University, Waurn Ponds, VIC 3216, Australia $\dagger$ Electronic supplementary information (ESI) available. See DOI: $10.1039 / \mathrm{c} 8 \mathrm{ra03166e}$ capability, wide range $\mathrm{pH}$ tolerance and independently tailorable support layer and active layer properties. ${ }^{15-18}$ Despite extensive study in TFC-PA membrane synthesis, the lack of high-performance membrane is a bottleneck in the development FO process.

Commonly, a desirable FO membrane requires (1) an ultrathin highly selective layer, (2) a highly porous and hydrophilic support layer for water transfer and low internal concentration polarization (ICP) and (3) excellent antifouling properties. ${ }^{19-23}$ However, the low water flux and membrane fouling are still two key problems in FO. ${ }^{\mathbf{1 8 , 2 4 - 2 8}}$ Water molecules have to pass through the active layer, thus the thickness and hydrophilicity changes in membranes can make water transport faster by reducing the mass transfer resistance. It has been reported that the thinner and more hydrophilic polyamide layer improves the water permeability and anti-fouling property of the TFC membrane. ${ }^{29-32}$ In addition, the reverse solute flux, namely, the salt diffusion from the draw solution to the feed solution, also has critical impacts on FO flux and membrane fouling. Therefore, an ultra-thin and hydrophilic active layer with desirable solute rejection, high water flux and antifouling property is a critical criterion for fabricating high-performance FO membranes. 
In the past years, mussel-inspired dopamine (DA) or polydopamine (PDA) chemistry, has opened a new route to highperformance membrane fabrication. PDA has been recently used to improve fouling resistance of ultrafiltration (UF) ${ }^{33}$ and RO membranes ${ }^{34}$ by increasing their hydrophilicity of either the selective layer or the support layer. Xi et al. designed a novel method of surface modification with DA and polyethylene (PE) to significantly enhance the permeability of the membranes. ${ }^{35}$ Zhao et al. proved that sole DA in the aqueous solution in the interfacial polymerization process improved the membrane structural and chemical stability, yet sacrificed the membrane salt rejection..$^{36}$ Recently, Huang et al. ${ }^{37}$ prepared three kinds (coated on top, bottom and dual surface substrate) of PDA modified substrates before the formation of TFC membranes, and a reduction of reverse solute flux was observed for the PDA coated top surface membranes. Han et al. ${ }^{\mathbf{1 8}}$ prepared TFC FO membranes based on PDA modified polysulfone top surface of substrates, the thickness of the PA layer decreased while salt rejection increased with a short PDA coating time on membrane substrates. Xu et al. ${ }^{38}$ reported the incorporation of DA as a coreactant for FO membrane fabrication by introducing DA into $m$-phenylenediamine (MPD) solution. The prepared new membrane showed improved water flux but increased reverse salt flux and PA layer thickness compared with the control membrane. These different trends of salt permeability and PA layer thickness may be attributed to different dopamine concentrations mixed with MPD monomers which triggers dopamine self-polymerization difference with different PDA particle size thus alters the process of interfacial polymerization. Therefore, the effect of different dopamine concentrations mixed with MPD in the aqueous phase on FO membrane properties and performance should be investigated.

In this study, we fabricated DA-incorporating TFC FO membranes via manipulating the concentration of DA in MPD constantly dissolved solution (DA-MPD mixture) as the aqueous phase during interfacial polymerization to get a better understanding of high-performance DA-related FO membrane synthesis. The DA self-polymerization produces different size of PDA particles in different DA-MPD mixtures were studied via adjusting the concentrations of DA. State-of-the-art characterization techniques were applied to confirm the PA layer formation mechanism, including attenuated total reflection Fourier transform infrared (ATR-FTIR), X-ray photoelectron spectroscopy (XPS), field-emission scanning electron microscope (FESEM), atomic force microscope (AFM). This study offers significant insights into developing high-performance FO membranes by exploring the relationship between the dopamine self-polymerization in aqueous phase and FO performance.

\section{Experimental}

\subsection{Materials}

Polysulfone beads (PSf, average molecular weight (MW) $\sim 22$ $\mathrm{kDa}$, Aldrich, USA), polyvinylpyrrolidone (PVP, average MW 10 $\mathrm{kDa}$ ), 1-methyl-2-pyrrolidinone (NMP, 99\%, RCI LABSCAN LIMITED, Thailand) were used to make polysulfone substrate.
$m$-Phenylenediamine flakes (MPD, Aldrich, USA, 99\%) was dissolved in aqueous phase. 1,3,5-Benzenetricarbonyl chloride (TMC, Alfa Aesar ${ }^{\circledR}$, England, 98\%) was dispersed in hexane, (Univar, Redmond, WA). Dopamine hydrochloride (International Laboratory, USA, 99\%). For membrane performance tests, sodium chloride ( $\mathrm{NaCl}$, ACS reagent) was dissolved in deionized water (DI) obtained from a Milli-Q ultra pure water purification system (Millipore, Billerica, MA).

\subsection{Preparation of polysulfone substrates}

A desired micro-structure substrate was fabricated using PSfPVP mixed casting solution. To prepare the casting solution, a mixed solvent system containing $15 \mathrm{~g}$ PSf, $8 \mathrm{~g}$ PVP and $77 \mathrm{~g}$. NMP was magnetically stirred for $24 \mathrm{~h}$ and then left standing for about $12 \mathrm{~h}$ at room temperature for degassing. ${ }^{39,40} \mathrm{~A}$ thin film $(195 \pm 10 \mu \mathrm{m})$ of the obtained cast solution was cast onto a clean and smooth glass plate by a membrane casting knife (RK Print Coat Instruments Ltd., UK). The whole composite was exposed in the air for about $10 \mathrm{~s}$ before it was immersed into a $60{ }^{\circ} \mathrm{C}$ DI water bath for $30 \mathrm{~min}$ to initiate the phase inversion. Afterwards, the membrane was removed from the water bath, thoroughly rinsed with Milli-Q water and then transferred to a $4{ }^{\circ} \mathrm{C}$ DI water bath for storage and later use.

\subsection{Preparation of thin film composite (TFC) membranes}

The TFC composite membranes were prepared via interfacial polymerization between the mixed-amine (MPD and dopamine) solution and TMC on the surface of the PSf substrates, shown in Fig. 1. Specifically, a phosphate buffered solution (PBS) was prepared by mixing $3.0 \mathrm{wt} \%$ MPD and different concentrations of dopamine $(0.0,0.01,0.05,0.10$ and $0.30 \mathrm{wt} \%)$. At the same time, change of DA self-polymerization, namely, PDA particle sizes in the aqueous phase was analysed by a zetasizer (Zetasizer Nano ZSP, Malvern, UK). The PSf substrate was immersed in the prepared solution for $30 \mathrm{~min}$ to ensure complete soaking and appropriate self-polymerization of dopamine (form PDA), ${ }^{36}$ then the excess solution was removed by slowly moving an air-knife (Cincinnati, Ohio USA) from one end to the another within $30 \mathrm{~s}$. Then, the substrate was dipped in TMC solution $(0.15 \mathrm{wt} \%$ in hexane) for $60 \mathrm{~s}$, initiating interfacial polymerization. Next, the substrate was taken from the hexane organic phase and set vertically for $2 \mathrm{~min}$ to evaporate excess organic solution. Afterwards, a dry curing process was proceeded by putting the asprepared substrate into an oven at a temperature of $90{ }^{\circ} \mathrm{C}$ for 5 min. Finally, the obtained composite membranes were washed and stored in $4{ }^{\circ} \mathrm{C}$ DI water until they were tested. These resultant membranes were denoted as TFC-0, TFC-1, TFC-2, TFC-3 and TFC-4, containing $0,0.01,0.05,0.10$ and $0.3 \mathrm{wt} \%$ of dopamine in aqueous phase, respectively.

\subsection{Characterizations of thin film composite (TFC) membranes}

The morphology of the membrane surfaces and cross-sections (freeze-dried, fractured in liquid nitrogen) was observed by FESEM (Merlin ZEISS GEMINI2) operating at $5 \mathrm{kV}$ and a working distance of 6.5-7.0 $\mathrm{mm}$. For the PA layer thickness 


\section{Dopamine, Polydopamine and MPD}
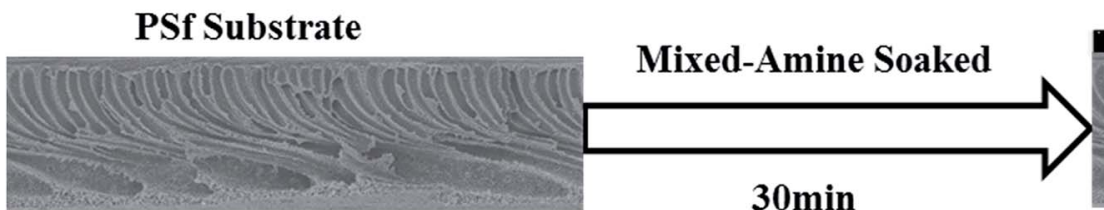

$30 \mathrm{~min}$
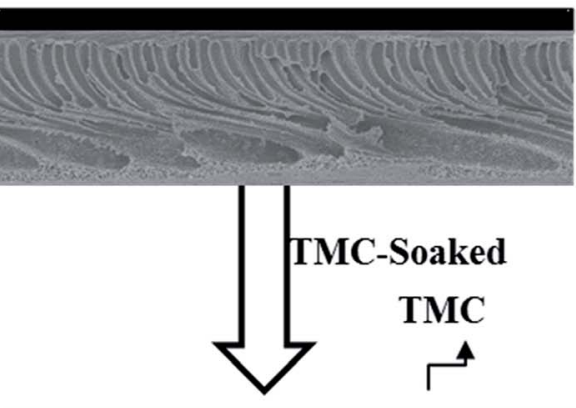

TFC Membrane

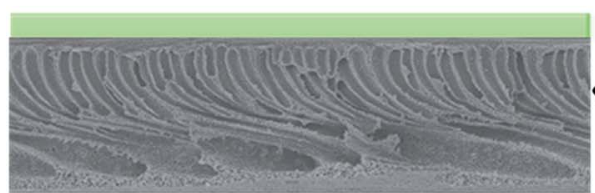

Interfacial Polymerization

Fig. 1 Flow diagram of TFC membrane synthesis.

tests, 10 random measurements were conducted based on three different membranes in cross-section FESEM images. Surface roughness was measured by AFM (Asylum Research Cypher, Cypher S, USA). A tapping mode was operating at $20 \pm 0.5{ }^{\circ} \mathrm{C}$, with the images taken in the range of $5 \mu \mathrm{m} \times 5 \mu \mathrm{m}$. The mean roughness was used for membrane surface characterization. Surface chemical characterization and the degree of crosslinking of the skin layers were determined by XPS (ESCALab220IXL, VG Scientific Company Ltd., England) with an $\mathrm{Al} / \mathrm{K} \alpha$ $(h \nu=1486.6 \mathrm{eV})$ anode mono X-ray source. Water contact angles were measured using a contact angle system (Dataphysics OCA 20 ) by placing a $2 \mu \mathrm{L}$ droplet on a dried membrane surface. For each membrane, 10 measurements were performed for each of three independently casted membranes. ATR-FTIR spectroscopy instrument (Thermo Scientific Nicolet 6700) was used to confirm the change of the functional groups and element binding states of the polyamide skin layer.

\subsection{FO performance tests}

FO performance experiments were tested with a lab-scale filtration unit with an effective membrane area of about 42.0 $\mathrm{cm}^{2}$ (Fig. 2). A commercial virgin PTFE cell (CF042-FO, Sterlitech Co.) was used to hold the membrane, having two rectangular channels with dimensions of $92.1 \mathrm{~mm}$ in length, $45.7 \mathrm{~mm}$ in width and $2.3 \mathrm{~mm}$ in depth. Co-current cross-flow was selected and the flow velocities were $4.9 \mathrm{~cm} \mathrm{~s}^{-1}$ for both the feed

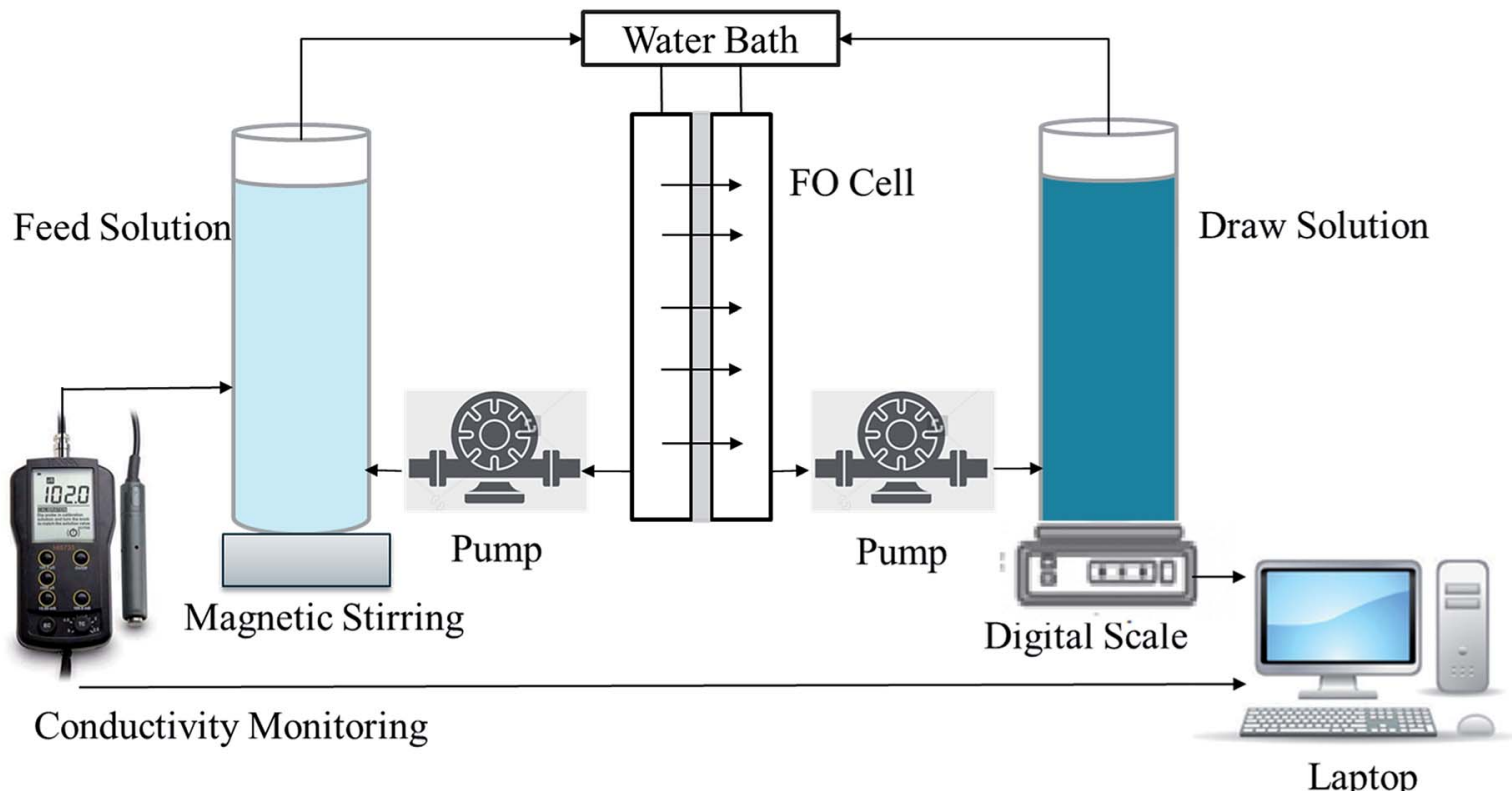

Fig. 2 Schematic diagram of FO performance testing system. 


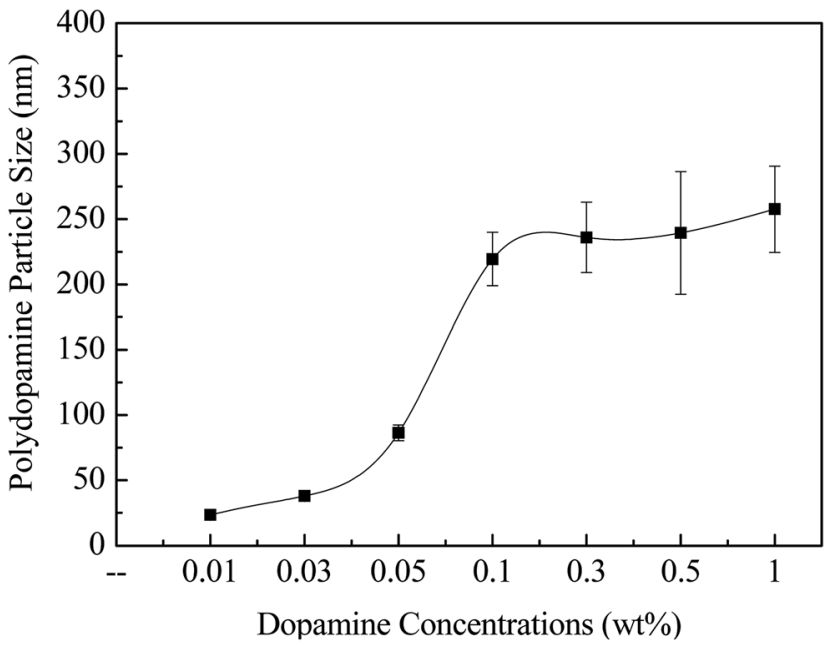

Fig. 3 Polydopamine particle size as a function of the dopamine concentration. The testing was performed in $30 \pm 1 \mathrm{~min}$ and $3.0 \mathrm{wt} \%$ MPD monomers were dissolved in PBS solutions to simulate the environment in interfacial polymerization.

and draw solutions. The temperatures of the feed and draw solutions were controlled at $20 \pm 0.5{ }^{\circ} \mathrm{C}$. $\mathrm{NaCl}$ solutions with different concentrations $(0.1,0.5,1.0,2.0 \mathrm{M})$ were used as the draw solutions and a digital balance was connected a computer to monitor weight change of the permeated water at $30 \mathrm{~s}$ intervals (ML4002, METTLER TOLEDO). DI water was used as the feed solutions and a conductivity meter (Con 110, Oakton Instruments) was used to monitor the conductivity change at $60 \mathrm{~s}$ intervals for calculating the reverse solute flux of the membrane. Membranes were tested under two different modes: active layer facing draw solution (AL-DS) mode, and active layer facing feed solution (AL-FS) mode. Each test was conducted for $60 \mathrm{~min}$ in triplicate.

The water permeation flux $\left(J_{\mathrm{w}}\right)\left(\mathrm{L} \mathrm{m} \mathrm{m}^{-2} \mathrm{~h}^{-1}, \mathrm{LMH}\right)$ was calculated by the following equation:

$$
J_{\mathrm{w}}=\frac{\Delta w}{\rho m_{\mathrm{e}} t}
$$

where $\Delta w(\mathrm{~kg})$ is the mass change of the draw solution over a period time $t(\mathrm{~h}), \rho$ is the density of water $\left(\mathrm{kg} \mathrm{L}^{-1}\right)$ and $m_{\mathrm{e}}$ is the effective membrane area $\left(\mathrm{m}^{2}\right)$.

The reverse solute flux, $\left(J_{\mathrm{s}}\right)\left(\mathrm{mmol} \mathrm{m} \mathrm{m}^{-2} \mathrm{~h}^{-1}\right)$, salt leakage or reverse diffusion from the draw solution to the feed solution, is an important parameter in FO determined by the increase of the feed solution conductivity.

$$
J_{\mathrm{s}}=\frac{\Delta C_{t} V_{t}}{m_{\mathrm{e}} t}
$$

where $\Delta C_{t}$ and $V_{t}$ are the change of feed solution concentration and volume the feed solution at the end of FO experiment, respectively.

\subsection{FO fouling experiments}

FO fouling experiments were tested using the TFC-0, TFC- 1 and TFC-4 membranes with the laboratory scale FO setup described in Section 2.5, based on the reported method..$^{21,30,41,42}$ The feed solution was made up of seawater collected from Briton Beach in Melbourne. The fouling experiments were performed under AL-FS mode with the same flow velocity $\left(4.9 \mathrm{~cm} \mathrm{~s}^{-1}\right)$ for both the feed and draw solutions. Baseline experiments were performed using DI water to measure the water flux declines derived solely from reverse solute flux and draw solute diluted with fresh FO membranes. $\mathrm{NaCl}$ solutions of different concentrations were used to generate the same initial FO water flux $\left(J_{\mathrm{w}_{0}}, 10 \mathrm{~L} \mathrm{~m}^{-2}\right.$ $\mathrm{h}^{-1}$ ). The fouling experiment was conducted at the same initial flux as the baseline experiment. Then, the fouling experiment data were corrected to eliminate the flux decline from reverse solute flux and draw solution dilution. This means the presented data demonstrate only the water flux decline due to membrane fouling. The baseline and fouling experiments were conducted up to $10 \mathrm{~h}$. To evaluate the extent of irreversible fouling, the membranes were washed for $30 \mathrm{~min}$ using DI water through the feed and draw compartments at a cross-flow velocity of $14.7 \mathrm{~cm} \mathrm{~s}^{-1}$. Ultimately, water flux of the washed FO membrane was measured under the same conditions as the baseline experiments.

\subsection{Determination of FO transport and structural parameters}

Separation parameters of the FO membranes, the water permeability coefficient $(A)$, salt permeability coefficient $(B)$, and structural parameter $(S)$ were evaluated by the classic method. ${ }^{43}$ The method includes a four-stage FO experiment, each stage utilizing a different draw solution concentration. The water permeation flux $\left(J_{\mathrm{w}}\right)$ and reverse solute flux $\left(J_{\mathrm{s}}\right)$ were measured through non-linear regression based on eqn (3) and (4), in each experimental stage. The presented data are the average values based on triplicated measurements.

$$
\begin{aligned}
& J_{\mathrm{w}}=A\left\{\frac{\pi_{D} \exp \left(-\frac{J_{\mathrm{w}} S}{D}\right)-\pi_{F}}{1+\frac{B}{J_{\mathrm{w}}}\left[1-\exp \left(-\frac{J_{\mathrm{w}} S}{D}\right)\right]}\right\} \\
& J_{\mathrm{s}}=B\left\{\frac{C_{D} \exp \left(-\frac{J_{\mathrm{w}} S}{D}\right)-C_{F}}{1+\frac{B}{J_{\mathrm{w}}}\left[1-\exp \left(-\frac{J_{\mathrm{w}} S}{D}\right)\right]}\right\}
\end{aligned}
$$

where $D$ is the bulk diffusion coefficient of the draw solute and $F$ represents for feed solution.

\section{Results and discussion}

\subsection{The DA self-polymerization process in the aqueous phase}

To select suitable DA concentrations for interfacial polymerization, the relationship between PDA particle sizes and DA concentrations was studied. Self-polymerization of DA forms PDA particles, and the reaction activity is high in the alkaline condition, reaching the highest level at $\mathrm{pH} 8.5 .^{35}$ Therefore, PBS at $\mathrm{pH} 7$ was prepared to dissolve MPD and DA, which helps keep a mild and controllable self-polymerization of DA. ${ }^{35,36}$ 

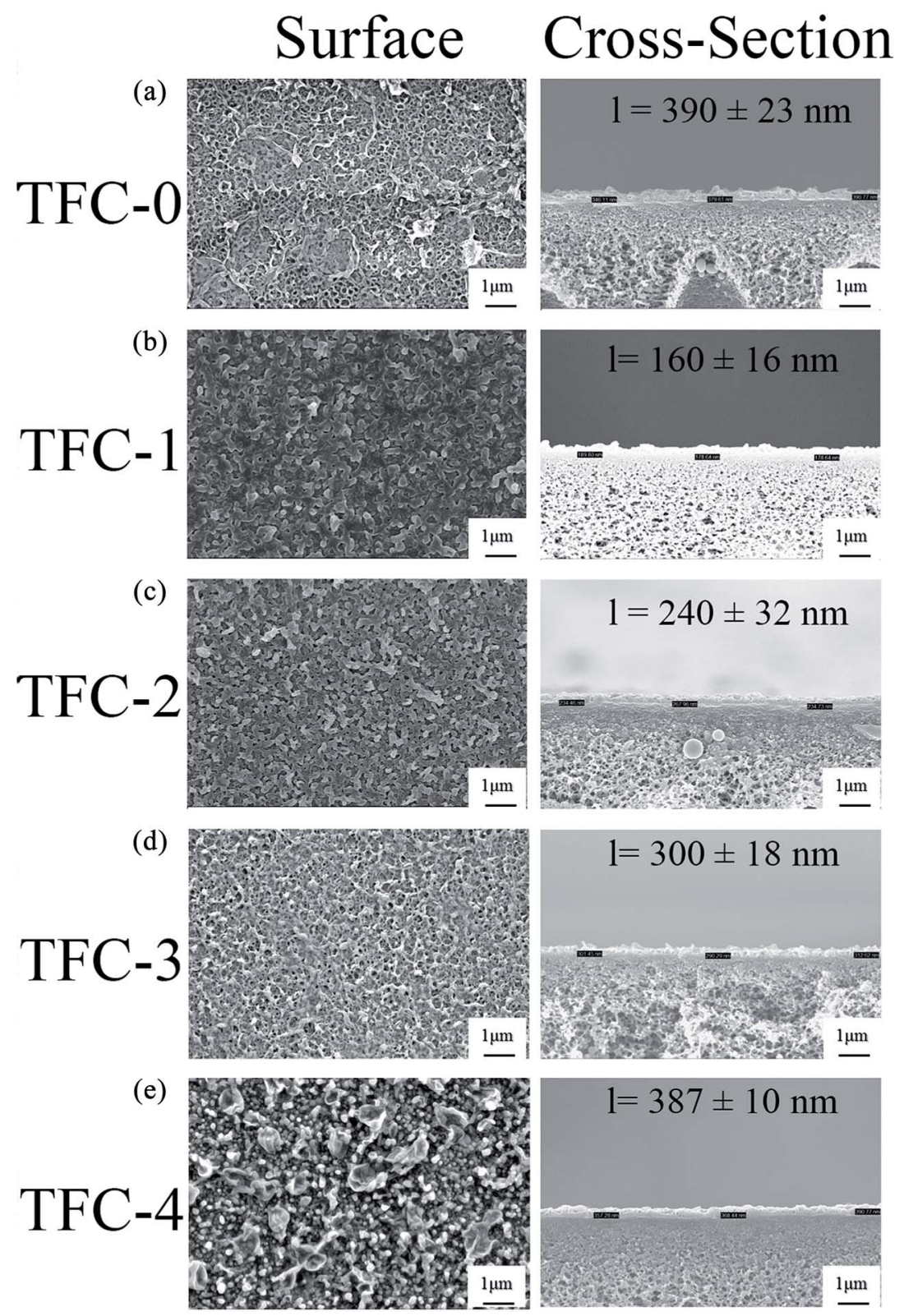

\section{AFM}
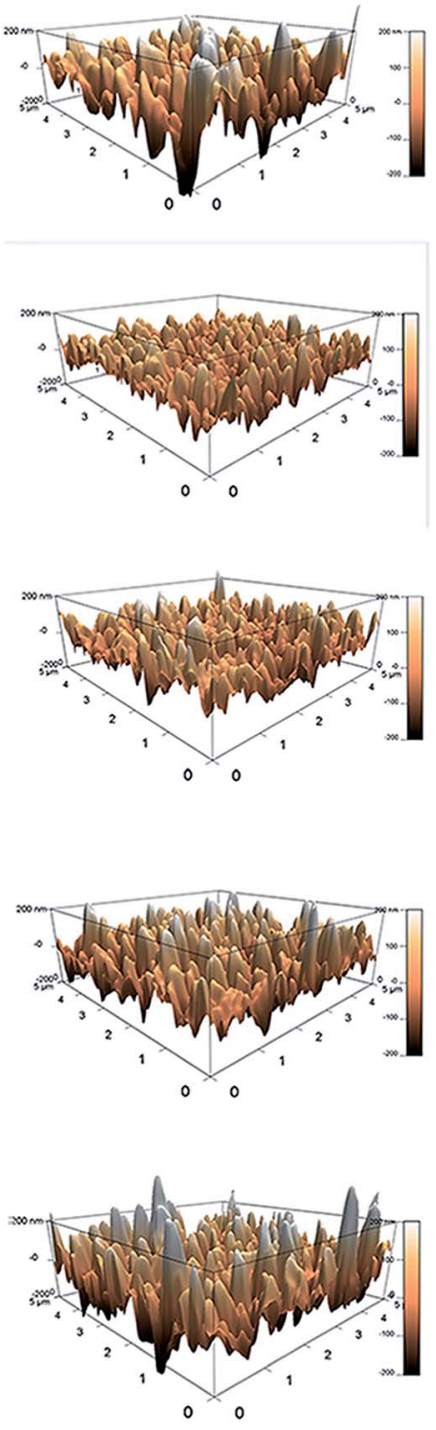

Fig. 4 SEM and AFM images of (a) TFC-0, (b) TFC-1, (c) TFC-2, (d) TFC-3, and (e) TFC-4, in which / means PA layer thickness.

Fig. 3 shows the relationship between PDA particle sizes and DA concentrations in the aqueous phase. The PDA particles sizes ascended as the DA concentration increased. As the DA concentration increased from 0.01 to $0.10 \mathrm{wt} \%$, a significant dopamine self-polymerization was observed, with the PDA particle sizes increased from $23.4 \mathrm{~nm}$ at $0.01 \mathrm{wt}$ to $219.4 \mathrm{~nm}$ at $0.10 \mathrm{wt} \%$. Further increasing the DA concentration from $0.30 \mathrm{wt} \%$ to $1.0 \mathrm{wt} \%$ only resulted in a very small increase in PDA particle sizes, from $236.0 \mathrm{~nm}$ to $257.6 \mathrm{~nm}$ with much higher error bars, indicating the higher agglomeration due to the DA self-polymerization. Thus, we chose $0.01 \mathrm{wt} \%$ and $0.05 \mathrm{wt} \%$, low DA concentration represented a relatively lowdegree dopamine self-polymerization and small PDA particles in aqueous phase, while $0.10 \mathrm{wt} \%$ and $0.30 \mathrm{wt} \%$ high DA concentration represented high-degree DA self-polymerization and big PDA particles in the aqueous phase in the following work.

\subsection{Effects of DA self-polymerization on membrane morphologies}

SEM images in Fig. 4 shows that FO membrane surfaces displayed "ridge and valley" and some "leaves" characteristics, which is consistent with the typical morphology of an interfacial polymerized PA membrane. ${ }^{17,18,21,44}$ An additional thin PA layer was observed on top of the porous support layer through the cross-sectional SEM images, which proved the successful interfacial polymerization. Increase DA concentration leaded to the changes in both surface and cross-sectional morphology. 
Table 1 Water contact angles of the TFC FO membranes

\begin{tabular}{llllrl}
\hline Membranes & TFC-0 & TFC-1 & TFC-2 & TFC-3 & TFC-4 \\
\hline Water contact angle $\left(^{\circ}\right)$ & $76.9 \pm 3.3$ & $49.1 \pm 2.1$ & $48.6 \pm 1.7$ & $44.2 \pm 2.2$
\end{tabular}

With low DA concentration in the aqueous phase, that is, the DA self-polymerization degree was low, the "leaves" structure became more compact and denser, which is highly desirable for achieving high selectivity. In contrast, with a high-degree DA self-polymerization incorporation, the "leaves" structure became more loosely packed and rougher probably due to the excessive PDA particles aggregation on the membrane surface, which may compromise on the membrane salt rejection.

With incorporation of DA in low-degree self-polymerization, the average surface roughness $\left(R_{\mathrm{a}}\right)$ decreased from $68.1 \mathrm{~nm}$ for the TFC- 0 membrane to 43.8 and $48.2 \mathrm{~nm}$ for the TFC- 1 and TFC-2 membranes, respectively, which may be favourable for reducing the adhesion of contaminants. While the membranes incorporated with higher degree DA self-polymerizations, namely the TFC-3 and TFC-4 membranes show $R_{\mathrm{a}}$ values of 64.5 and $68.4 \mathrm{~nm}$, respectively, similar to the surface roughness of the nascent membrane. Apart from this, when compared with the control membrane, the PA layer thickness of the modified membranes increased from a half-reduced $(160 \mathrm{~nm})$ thickness to a similar thickness $(387 \mathrm{~nm})$ of the control membrane $(390$ $\mathrm{nm}$ ) when the concentration of DA was increased from $0.01 \mathrm{wt} \%$ to $0.30 \mathrm{wt} \%$. Generally, TMC monomers are less soluble in the aqueous phase, thus interfacial polymerization occurs in the organic phase. MPD monomers ${ }^{45}$ (Fig. S-1†) are required to diffuse from the aqueous phase to the organic phase to react with the TMC monomers. For the TFC- 1 and TFC- 2 membranes, the diffusion rate may be hindered due to the presence of small PDA particles in the aqueous phase and substrate pores, thus limited the polymerization reactions between MPD and TMC monomers, which led to the formation of thinner but compact active layers, similar to the recent published work "Turing structure" polyamide, that the existence of hydrophilic materials in aqueous phase would alter polyamide structure and morphology. ${ }^{\mathbf{4 6 , 4 7}}$ When the DA self-polymerization process increased significantly thus PDA particles were big enough to anchor on the substrate, more MPD monomers may be able to diffuse into the organic phase due to the less attractive force between MPD monomers and PDA particles. Thus, the PA layer thickness of the TFC-3 and TFC-4 membrane increased to approximately the same value of the controlled membrane. Moreover, attributed to the aggregation and steric hindrance of the big PDA particles due to high-degree DA selfpolymerization, loosely-packed and thick active layers were formed.

It is expected that the introduction of DA and PDA (after DA self-polymerization) with abundant amine and hydroxyl groups may result in an enhanced surface hydrophilicity. The water contact angle results from Table 1 confirmed these hypotheses. The membrane surface hydrophilicity increased with increasing the DA concentration in the aqueous phase. The water contact angle dropped from $76.9^{\circ}$ of the control membrane to $49.1^{\circ}$ of the TFC- 1 membrane, and further decreased to $41.7^{\circ}$ of the TFC4 membrane. The improved hydrophilicity of the DAincorporated membrane is mainly attributed to the hydrophilic nature of PDA. ${ }^{33,48}$ The TFC membranes modified with low DA incorporation and self-polymerization (TFC-1 and TFC2) had more compact surfaces (see Fig. 4). The TFC-3 and TFC-4 membrane modified by relatively high DA concentrations and self-polymerization showed a better hydrophilicity likely due to the capillary effect of the rougher membrane surface.

\subsection{Effects of DA self-polymerization on membrane chemical properties}

ATR-FTIR results of the PSf substrate and TFC membranes are shown in Fig. 5. The characteristic bands of polyamide at $\sim 1544,1610$ and $\sim 1650 \mathrm{~cm}^{-1}$, were observed in all TFC
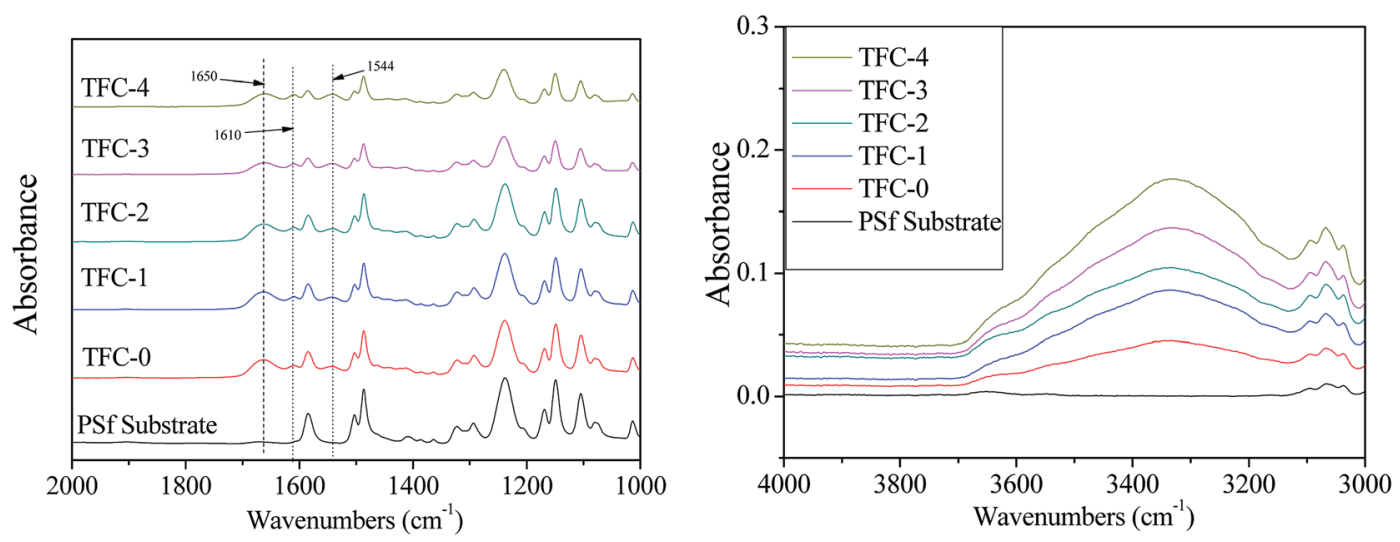

Fig. 5 ATR-FTIR images of membranes PSf substrate, TFC-0, TFC-1, TFC-2, TFC-3 and TFC-4. 
(a)

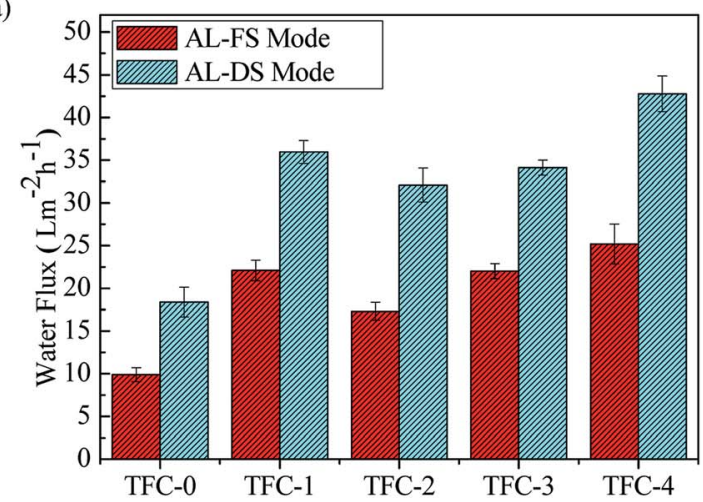

(b)

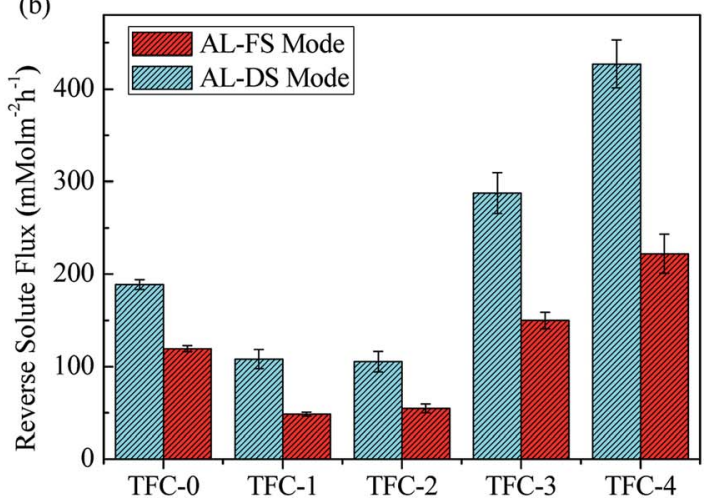

Fig. 6 Performance of the TFC membranes in FO performance tests, (a) water flux and (b) reverse solute flux in both AL-FS and AL-DS mode with $2 \mathrm{M} \mathrm{NaCl}$ as draw solution and DI water as the feed solution.

membranes, which correspond to the aromatic ring breathing, amide I band and amide II band, respectively, indicating a successful formation of a thin rejection layer by interfacial polymerization..$^{30,49-51}$ Moreover, the increase in the peak intensity of hydroxyl groups at about $3100-3600 \mathrm{~cm}^{-1}$ was also found in all the modified TFC membranes, which are attributed to $\mathrm{O}-\mathrm{H}$ and $\mathrm{N}-\mathrm{H}$ stretching vibration in PDA, leading to more hydrophilic membrane surfaces (Table 1$)^{37}$

XPS measurements were carried out to further confirm the chemical changes of the TFC membranes. XPS is a highly sensitive technique that has the ability to analyze the elemental composition and chemical binding information for the top 5$10 \mathrm{~nm}$ depth of the membrane surface, which can provide information about the mechanism of reaction of interfacial polymerization and cross-linking degree of the PA layer. ${ }^{30,38,45}$ Fig. S- $2 \dagger$ displays the XPS spectra of PSf substrate and TFC membranes, and three major emission peaks were detected at $285.0 \mathrm{eV}$ for C1s, $532.4 \mathrm{eV}$ for O1s and $400 \mathrm{eV}$ for N1s. The O/N ratio of all the DA-incorporated TFC membranes was smaller than that of the control TFC membrane, and it increased with the increase of DA self-polymerization process, which also confirmed the successful introduction of DA in the membrane surface. Typically, $\mathrm{O} / \mathrm{N}$ ratio is considered to be an insight into the cross-linking degree of PA layers. ${ }^{52,53}$ However, in this work, because of the significant changes in the $\mathrm{O} 1 \mathrm{~s}$ and N1s contents, $\mathrm{O} / \mathrm{N}$ ratio was not accurate enough to estimate the PA layer cross-linking degree. Therefore, the chemical bonding and their contents were resolved from C1s, N1s and Cl2p (Fig. S-3†) to speculate the crosslinking degree of PA layers.

For the high-resolution C1s, core-level XPS spectrum of the composite membrane, as shown in the Fig. $\mathrm{S}-3(\mathrm{a}-\mathrm{e}), \dagger$ the peaks at the bonding energy of $285.0,286.5$, and $288.2 \mathrm{eV}$ could be attributed to $\mathrm{C}-\mathrm{C} / \mathrm{C}-\mathrm{H}, \mathrm{C}-\mathrm{N}$ and $\mathrm{O}=\mathrm{C}-\mathrm{O} / \mathrm{O}=\mathrm{C}-\mathrm{N}$ functional groups, respectively. When the particle size of PDA went up from 23.4 to $236.0 \mathrm{~nm}$, the $\mathrm{C}=\mathrm{O}$ proportion decreased from $9.90 \%$ to $6.31 \%$, while the $\mathrm{C}-\mathrm{N}$ proportion increased from $36.00 \%$ to $46.03 \%$. The reduce of $\mathrm{C}=\mathrm{O} / \mathrm{C}-\mathrm{N}$ ratio revealed that low degree DA self-polymerization in the aqueous phase could increase the cross-linking degree of the PA layer. ${ }^{54}$ However, as the DA self-polymerization continued to increase, this ratio increased to 0.456 , indicating a loose PA layer produced. The $\mathrm{N} 1 \mathrm{~s}$ spectra were convoluted into two peaks including $\mathrm{C}-\mathrm{N}^{+}$and $\mathrm{C}-\mathrm{N}$ components with the binding energies of approximately 402.0 and $399.8 \mathrm{eV}$, respectively, as shown in Fig. S-3(f-j). $\dagger$ The molar ratios of the $\mathrm{C}-\mathrm{N}^{+} /\left(\mathrm{C}-\mathrm{N}^{+}+\mathrm{C}-\mathrm{N}\right)$ can be calculated to analyse the PA layer cross-linking degree. ${ }^{55}$ The calculated ratios were 12.06, 4.36, 5.36, 10.58 and 19.32, which represented the samples TFC-0, TFC-1, TFC-2, TFC-3 and TFC-4, respectively. These relative values demonstrated that as the DA concentration increased, more radicals of the monomers remain unreacted. Therefore, the fully crosslinking structure of the polyamide was increased initially but reduced eventually.

The chlorine (Cl2p) element detected in the polyamide could be assigned to the hydrolysis of the unreacted acyl chloride groups and the TMC monomers in the surface layer.$^{56}$ Moreover, the spectra of Cl2p were resolved into three peaks, ${ }^{55}$ as illustrated in Fig. S-3(k)-(o), $\dagger$ consisting of $\mathrm{Cl}_{2} \mathrm{p}_{3 / 2}(\sim 197 \mathrm{eV})$ and $\mathrm{Cl}_{2} \mathrm{p}_{1 / 2}(\sim 198.7 \mathrm{eV})$ doublets divided from the Cl2p core-level spectrum and C-Cl2p at $200.0 \mathrm{eV}$, which represent chloride in TMC monomers that did not completely participate in the polymeric reaction. The molar ionization ratio of $\mathrm{Cl}$, defined as $\mathrm{Cl}^{-} /\left(\mathrm{C}-\mathrm{Cl}+\mathrm{Cl}^{-}\right)$, represented the cross-linking degree for PA layer. ${ }^{55}$ Accordingly, the calculated values were 82.49, 98.64, 92.5, 66.48 and 73.06, which represent the samples TFC-0, TFC1, TFC-2, TFC-3 and TFC-4, respectively.

Based on the findings from XPS analysis, combining with the membrane surface morphological analysis (Fig. 4), it is clear that dense, smooth and highly crosslinked surfaces were produced when incorporated with DA in low-degree self-polymerization and loosely-packed and rough membrane surfaces were formed with DA in high-degree self-polymerization.

\subsection{Effects of DA self-polymerization on FO membrane performance}

Fig. 6a illustrates the FO performance of membranes with different DA self-polymerizations under AL-DS and AL-FS modes using DI water and $2 \mathrm{M} \mathrm{NaCl}$ as the feed and draw solutions, respectively. In the AL-DS mode, the benchmark TFC0 membrane showed a water flux of $18.38 \mathrm{LMH}$. When DA in 
Table $2 J_{S} / J_{W}\left(m_{m o l} L^{-1}\right)$ ratio for TFC membranes with under AL-FS mode and AL-DS mode ${ }^{a}$

\begin{tabular}{lllrr}
\hline Membranes & TFC-0 & TFC-1 & TFC-2 & TFC-3 \\
\hline AL-FS mode & $12.18 \pm 1.35$ & $2.21 \pm 0.21$ & $3.19 \pm 0.47$ & $6.85 \pm 0.68$ \\
AL-DS mode & $10.37 \pm 1.26$ & $3.02 \pm 0.39$ & $3.32 \pm 0.55$ & $14.34 \pm 1.71$ \\
a Feed solution: DI water. Draw solution 1 M NaCl. & & & & \\
\cline { 2 - 2 } & & &
\end{tabular}

Table 3 Comparison of the performance of various FO membranes

\begin{tabular}{|c|c|c|c|c|c|c|c|}
\hline Membrane & 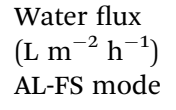 & $\begin{array}{l}\text { Reverse solute flux } \\
{\left[\mathrm{mmol} \mathrm{m}^{-2} \mathrm{~h}^{-1}\right]} \\
\text { AL-FS mode }\end{array}$ & $\begin{array}{l}\text { FO selectivity } \\
{\left[J_{\mathrm{s}} / J_{\mathrm{w}}\left(\mathrm{mmol} \mathrm{L}^{-1}\right)\right]}\end{array}$ & Feed solution & Draw solution & $S(\mu \mathrm{m})$ & Reference \\
\hline HTI-CTA-HW ${ }^{a}$ & 9.03 & 91.37 & 10.15 & $10 \mathrm{mM} \mathrm{NaCl}$ & $0.5 \mathrm{M} \mathrm{NaCl}$ & 481 & 54 \\
\hline CTA-W ${ }^{a}$ & 5.0 & 50.00 & 10.00 & $10 \mathrm{mM} \mathrm{NaCl}$ & $0.5 \mathrm{M} \mathrm{NaCl}$ & 473 & 54 \\
\hline CTA-NW $^{a}$ & 4.4 & 10.34 & 2.35 & $10 \mathrm{mM} \mathrm{NaCl}$ & $0.5 \mathrm{M} \mathrm{NaCl}$ & 541 & 54 \\
\hline TFC & 12.5 & 86.21 & 6.70 & DI water & $1.0 \mathrm{M} \mathrm{NaCl}$ & 370 & 20 \\
\hline TFNC-2 & 18.1 & 139.65 & 7.76 & DI water & $1.0 \mathrm{M} \mathrm{NaCl}$ & 148 & 40 \\
\hline Hollow fiber TFC & 34.5 & 170.17 & 4.93 & DI water & $2.0 \mathrm{M} \mathrm{NaCl}$ & 261 & 55 \\
\hline TFC & 47.5 & 213.7 & 4.50 & DI water & $2.0 \mathrm{M} \mathrm{NaCl}$ & 238 & 56 \\
\hline SPEK/PSF/TFC & 35 & 120 & 3.45 & DI water & $2.0 \mathrm{M} \mathrm{NaCl}$ & 107 & 27 \\
\hline PAN & 28 & 155.2 & 5.54 & DI water & $1.5 \mathrm{M} \mathrm{NaCl}$ & 290 & 57 \\
\hline TFC-PSfPDA-1h & 7.5 & 13.97 & 1.86 & DI water & $1.0 \mathrm{M} \mathrm{NaCl}$ & 1510 & 18 \\
\hline TFC DA-modified & 50.5 & 140 & 2.77 & DI water & $1.0 \mathrm{M} \mathrm{NaCl}$ & 67.1 & 34 \\
\hline TFC-0 & 7.58 & 84.15 & 12.18 & DI water & $1.0 \mathrm{M} \mathrm{NaCl}$ & 635 & Current study \\
\hline TFC-1 & 15.09 & 32.77 & 2.21 & DI water & $1.0 \mathrm{M} \mathrm{NaCl}$ & 176 & Current study \\
\hline
\end{tabular}

${ }^{a}$ The FO membrane was cut from a Hydrowell@ module (denoted as CTA-HW), other two membranes were received as flat coupons from Hydration Technology Innovations (HTI), either supported by a polyester woven fabric (denoted as CTA-W) or a non-woven fabric (denoted as CTA-NW).

low-degree self-polymerization was incorporated in the aqueous phase, the water flux was enhanced and reached 35.97 LMH for the TFC-1 membrane because of a thin PA layer and enhanced hydrophilicity property on the membrane surface. Further increase the self-polymerization of DA caused a slight reduction in water flux down to $32.11 \mathrm{LMH}$ for the TFC-2 membrane, which could be attributed to the slightly increased active layer thickness compared with TFC- 1 . The TFC-3 and TFC-4 membranes showed significant improvement in water flux than the nascent membrane, probably can be assigned to the combined factors of loosely-packed structures, lower crosslinking degree and hydrophilic surface. In conclusion, all the DA-incorporated TFC membranes showed great improvement in water flux compared with the TFC-0 membrane, where a flux increase of $\sim 133 \%$ in the AL-DS mode and $\sim 154 \%$ in the AL-FS mode was achieved by TFC-4 membrane.

Fig. 6b shows the reverse solute flux under AL-FS and AL-DS modes for TFC series membranes, respectively. Reverse solute flux decreased sharply to $48.46 \mathrm{mmol} \mathrm{m}^{-2} \mathrm{~h}^{-1}$ and $108.16 \mathrm{mmol}$ $\mathrm{m}^{-2} \mathrm{~h}^{-1}$ under AL-FS and AL-DS modes for TFC-1 membrane, respectively. However, as the DA self-polymerization increased significantly, the increases of reverse solute flux of TFC membranes were obvious when compared with the benchmark in the current study. This phenomenon may be attributed to the PDA aggregation in high DA concentrations, which greatly hampered the interfacial polymerization process by the steric hindrance of PDA aggregations, leading to a loosely-packed intra-structure and low cross-linking surface with a poor salt rejection, ${ }^{36,38}$ which was confirmed by SEM (Fig. 4).

The reverse solute flux/water flux $\left(J_{\mathrm{s}} / J_{\mathrm{w}}\right)$ ratio of the resultant TFC membranes are summarized in Table 2. A smaller $J_{\mathrm{s}} / J_{\mathrm{w}}$ usually indicates a higher FO selectivity. ${ }^{57,58}$ Generally, the error bar of $J_{\mathrm{s}} / J_{\mathrm{w}}$ is comparatively large because of the sample variation. However, a trend of selectivity for both AL-FS mode and AL-DS mode can still be observed. A great increase of $J_{\mathrm{s}} / J_{\mathrm{w}}$ as the PDA particle size went up, because of more PDA aggregations were formed and embedded into the PA layer, which then decreased the membrane selectivity greatly. Whereas, with lowdegree DA self-polymerization incorporation in the aqueous phase, the selectivity improved greatly for TFC-1 and TFC-2 membrane, and a lower value obtained for TFC- 1 . The improvement of selectivity and breaking the well-known tradeoff of "selectivity and permeability" for TFC- 1 and TFC- 2 may be due to the enhanced hydrophilic surface, thin and high cross-linking of the PA layer, where water molecules can permeate with lower resistance but rejecting salt behind. To be more specific, the incorporated small PDA particles in water phase hindered the diffusion of MPD monomers, thus a thinner active layer was formed, its thickness reduced from $390 \mathrm{~nm}$ to $160 \mathrm{~nm}$ compared to the control membrane, this is similar to Han's work, ${ }^{18}$ that a thinner active layer would reduce the water transfer resistance thus increasing FO water flux. Besides, the 
(a)

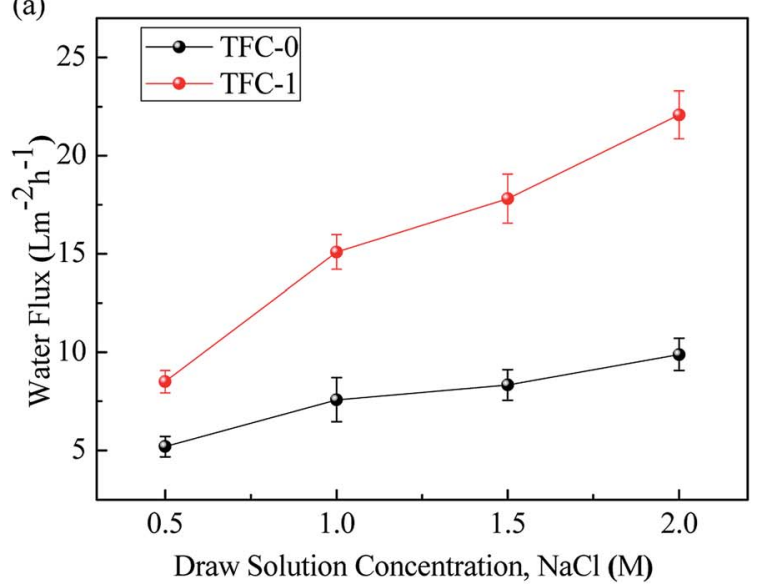

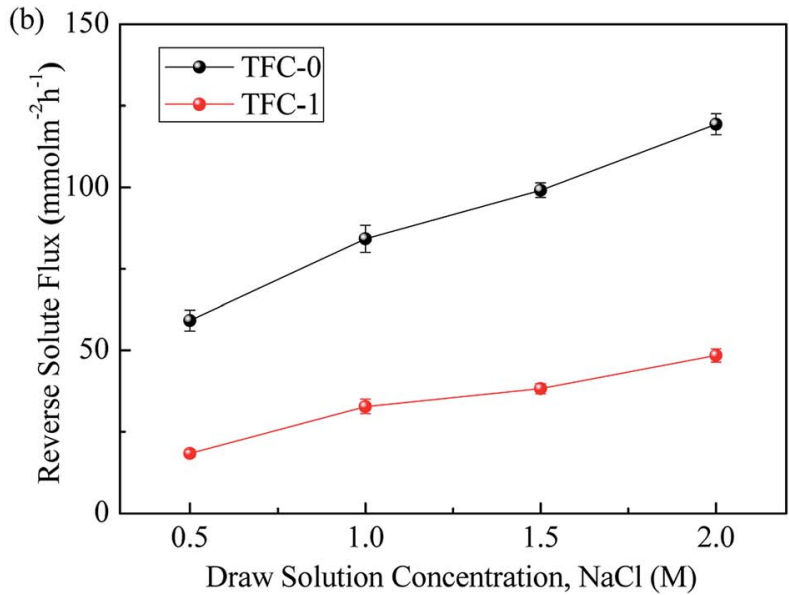

Fig. 7 (a) Water flux and (b) reverse solute flux for TFC-0 and TFC-1 membranes at AL-FS modes using DI water feed solutions and different concentrations of $\mathrm{NaCl}$ draw solutions.

incorporated polydopamine particles increased the membrane hydrophilicity compared to the control membrane, which is shown by a water contact angle drop, from $76.9^{\circ}$ of the control membrane to $49.1^{\circ}$ of the TFC- 1 membrane. It is well-known that a hydrophilic membrane surface would increase FO water flux. As for the reverse solute flux reduction, the TFC-1 membrane surface showed increased compactness compared to the control membrane (as supported by SEM images), which could reduce the subnanometer-scale cavities in polyamide layer. These observations and results are quite similar to Shi's recent work, ${ }^{59}$ they demonstrated that molecules with abundant hydroxyl groups, like tannic acid or polydopamine, affecting the polyamide layer formation and structure, specifically, forming a thinner and compact active layer, therefore, leading to the increased in both the water flux and rejection of the optimized membrane. Furthermore, $J_{\mathrm{s}} / J_{\mathrm{w}}$ of TFC- 1 membrane was much smaller than most TFC modified membranes, as shown in Table 3. In summary, the high water flux, low solute reverse flux and small $J_{\mathrm{s}} / J_{\mathrm{w}}$ attained using TFC- 1 and TFC- 2 membrane suggests that the introduction of DA in the aqueous phase with low selfpolymerization degree is an effective approach to optimize the membrane FO performance and AL-FS mode shows better FO performance for this new type of membrane. Then the FO performances of the controlled and best performing membrane TFC- 1 are further investigated under AL-FS modes by varying draw solution concentrations (0.5-2 $\mathrm{M} \mathrm{NaCl})$.

Fig. 7a shows that under AL-FS mode, the water fluxes of TFC1 membrane increase with $\mathrm{NaCl}$ concentration up to $2 \mathrm{M}$, which is the highest concentration usually being investigated in the literature everywhere. Moreover, the averaged water flux increment per $0.5 \mathrm{M}$ increase in the concentration of draw solution is approximately $4.15 \mathrm{LMH}$. At $2 \mathrm{M}$ draw solution concentration, water flux of the TFC-1 membrane was $123 \%$ higher than the benchmark, indicating a dramatically reduced ICP effect by introduction of dopamine in the aqueous phase. It is hypothesized that the small viscous PDA particles efficiently enhances the cross-linking of the PA layer which limits the reverse solute flux even at high draw solution concentration, thereby mitigating the internal concentration polarization and afford higher net osmotic driving force. As shown in Fig. 7b, the reverse solute fluxes of TFC- 0 and TFC- 1 as the benchmark under AL-FS mode reveal opposite trends. The mean reverse solute flux increment per $0.5 \mathrm{M}$ increase in draw solution for TFC- 1 was only around $10.04 \mathrm{mmol} \mathrm{m} \mathrm{m}^{-2} \mathrm{~h}^{-1}$ while the benchmark almost doubled (about $20.09 \mathrm{mmol} \mathrm{m}^{-2} \mathrm{~h}^{-1}$ ) due to more severe ICP phenomenon, which is consistent with the hypnosis that a more hydrophilic and dense active has formatted on the surface of the substrate. To provide useful comparison, the FO performances of the TFC-0 membrane, the TFC-control in current study, together with other membranes investigated in the literature are shown in Table 3. Compared with the TFC-0 (control) membrane, TFC- 1 membrane has exhibited superior water flux while maintaining relatively high selectivity. The current study demonstrates that DA in low-degree self-polymerization presents significant advantages over conventional additive in the polyamide layer in controlling the solute reverse diffusion.

Table 4 Summary of the transport properties of the TFC FO membranes

\begin{tabular}{llllllll}
\hline Membranes & $A\left(\mathrm{LMH} \mathrm{bar}^{-1}\right)$ & $B(\mathrm{LMH})$ & $S(\mu \mathrm{m})$ & $A / B\left(\mathrm{bar}^{-1}\right)$ & $R^{2}\left(J_{\mathrm{w}}\right)$ & $R^{2}\left(J_{\mathrm{s}}\right)$ & $\mathrm{CV}(\%)$ \\
\hline TFC-0 & 0.396 & 0.231 & 635 & 1.714 & 0.971 & 0.990 \\
TFC-1 & 0.476 & 0.051 & 176 & 9.333 & 0.988 & 0.984 \\
TFC-2 & 0.408 & 0.077 & 315 & 6.468 & 0.975 & 0.978 \\
TFC-3 & 0.604 & 0.205 & 196 & 2.946 & 0.971 & 0.977 \\
TFC-4 & 0.788 & 0.357 & 191 & 2.207 & 0.967 & 0.954
\end{tabular}


Table 5 Practical seawater characterization

\begin{tabular}{ll}
\hline Parameters (units) & Values \\
\hline Electrical conductivity $\left(\mathrm{ms} \mathrm{cm}^{-1}\right)$ & 51.2 \\
$\mathrm{pH}$ & 8.00 \\
$\mathrm{Na}^{+}(\mathrm{mM})$ & 469 \\
$\mathrm{Ca}^{2+}(\mathrm{mM})$ & 10.3 \\
$\mathrm{Mg}^{2+}(\mathrm{mM})$ & 53 \\
$\mathrm{~K}^{+}(\mathrm{mM})$ & 10.2 \\
\end{tabular}

\subsection{Effects of DA self-polymerization on the membrane separation properties}

Table 4 presents the water permeability coefficient $A$, salt permeability coefficient $B$ and $S$ value of TFC membranes with different-degree DA self-polymerization in aqueous phase. A non-monotonic behaviour of A value was observed when the DA self-polymerization degree increased. The benchmark TFC membrane showed a water permeability of $0.396 \mathrm{LMH} \mathrm{bar}{ }^{-1}$. After the addition of DA in the aqueous phase, the water permeability coefficient of TFC membrane increases significantly, and reached a high value of $0.476 \mathrm{LMH} \mathrm{bar}^{-1}$ for TFC-1 membrane. This trend is consistent with that derived from the FO performance experiments and due to the improved hydrophilicity of TFC membranes. Moreover, further increase the degree of DA self-polymerization led to a great increase of water permeability coefficient, for example, $0.788 \mathrm{LMH} \mathrm{bar}^{-1}$ for TFC4 , probably due to the formation of a loose active layer, resulting in a rapid pass through of water molecules. Compared to water permeability coefficient, the salt permeability coefficient showed a different trend. It decreased sharply from $0.231 \mathrm{LMH}$ for TFC-0 membrane to $0.051 \mathrm{LMH}$ and $0.077 \mathrm{LMH}$ for TFC-1 membrane and TFC- 2 membrane, respectively, which may be attributed to the formation of dense and high cross-linking active layers. Then the trend was followed by a great increase from 0.205 LMH (TFC-3) to 0.357 LMH (TFC-4). This trend for $B$ values is congruent with the behaviour of reverse solute flux, namely, a lower salt permeability exhibits a lower reverse solute flux.

As for the $S$ parameter, a critical parameter to evaluate FO membranes, decreases dramatically from 635 (TFC-0) to $176 \mu \mathrm{m}$ (TFC-1). According to the "three layer model" for TFC membrane $S$ parameters, namely, the PA layer, transition layer on the top of the substrate and the porous substrate, thus the decrease of PA layer thickness significantly decreases the $S$ parameter of TFC membrane. ${ }^{60}$ Moreover, the $A / B$ ratio is an important parameter to evaluate FO membrane selectivity; a higher $A / B$ is indicative of a greater selectivity and hence preferred. Table 4 reveals that the TFC- 1 and TFC- 2 membranes have similar $A / B$ ratios, which are $377-444 \%$ higher than the TFC-0 membranes, implying that these new type of membranes may show good performance in seawater desalination. Overall, the addition of DA in the aqueous phase allows a significant improvement in FO performance.

\subsection{Effects of DA self-polymerization on membrane FO antifouling performance}

Antifouling tests of TFC-0, TFC- 1 and TFC- 4 membranes was tested in the AL-FS mode with seawater collected from Briton Beach in Melbourne as the feed solution, seawater compositions are shown in Table 5. The decline in water flux for these three membranes was due to fouling and net osmotic pressure lost (draw solution dilution and feed solution concentration) (Fig. 8a). The TFC-1 and TFC-4 membrane exhibited much smaller water flux decline (about 14.4\% and 26.2\%) than the benchmark membrane (around 38.8\%). Fig. 8b shows higher flux recovery ratios for the TFC- 1 and TFC- 4 membranes, suggesting higher antifouling properties of the DA-incorporated membranes. The reverse solute accumulated at the active layer and feed solution interface reduced the net osmotic driving force, and hence reduced FO water flux. Organic foulants in seawater such as humic acid formed deformable gellike fouling layers accumulated at the active layer surface exacerbated these effects through the cake-enhanced osmotic
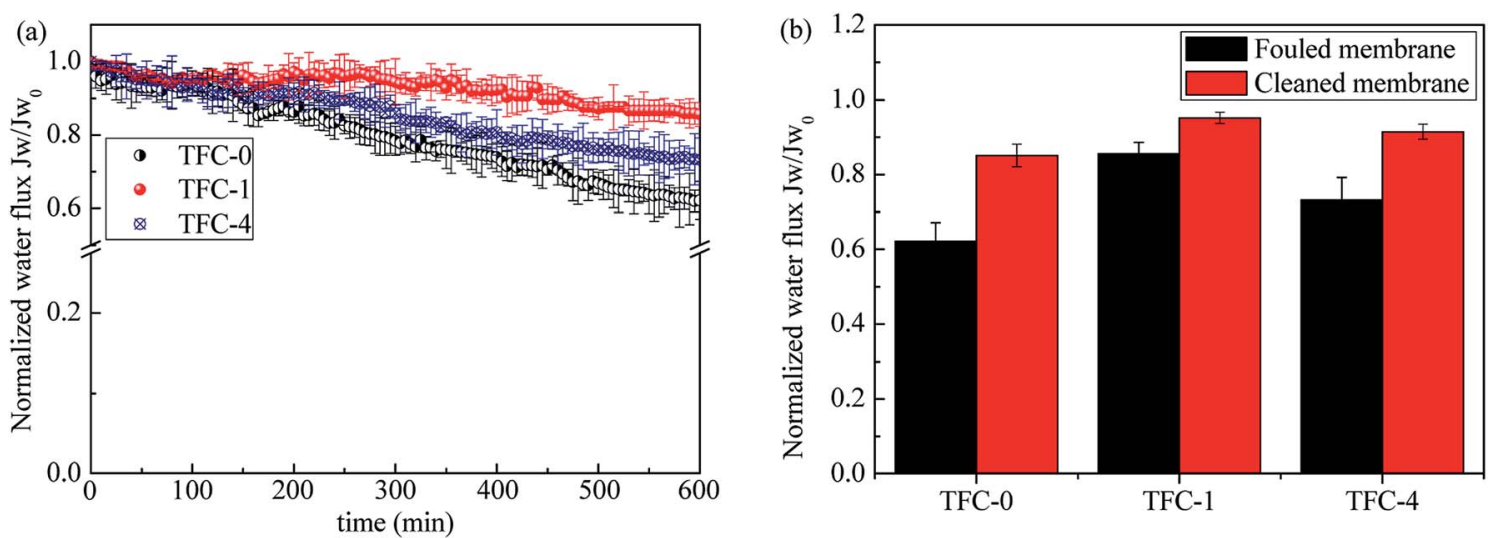

Fig. 8 (a) FO fouling curves for the benchmark membrane and the modified membranes (TFC-1 and TFC-4). The feed solution was supplemented with seawater collected from Briton Beach in Melbourne as model foulant. The initial permeate water flux of around $10 \mathrm{~L} \mathrm{~m} \mathrm{~m}^{-2} \mathrm{~h}^{-1}$. The cross flow velocities of the FS and DS were $4.9 \mathrm{~cm} \mathrm{~s}^{-1}\left(T=20 \pm 0.5^{\circ} \mathrm{C}\right.$, DS $\left.=\mathrm{NaCl} 0.5-4 \mathrm{M}\right)$, (b) comparison between the FO water flux of foaled membrane and recovered after the physical cleaning step. Crossflow velocity during cleaning step was $14.9 \mathrm{~cm} \mathrm{~s}^{-1}$. 
pressure (CEOP) ${ }^{61}$ As the TFC-4 membrane had a higher reverse solute flux than the TCF-1 membrane (Fig. 7b), it showed a lower flux compared with the TFC-1 membrane after fouling (Fig. 8b).

Moreover, the membrane surface properties can change the antifouling propensity. For instance, a hydrophilic membrane surface can reduce its interaction with organic foulants in seawater. A thin water film (i.e. a hydration layer) that forms on a hydrophilic surface through hydrogen bonding prevents accumulation of foulants, offering a lower fouling propensity. ${ }^{62}$ This mechanism introduced by DA can explain the lower water flux decline of the TFC- 1 and TFC-4 membranes. On the other hand, a smoother surface can enhance antifouling tendency of the membrane surface by minimizing foulants attachment and accumulation on the membrane surface. ${ }^{63}$ The fouling experiment results indicate that the higher surface hydrophilicity and smoothness of the TFC- 1 membrane resulted in a more advanced antifouling property compared with the TFC-4 membrane.

\section{Conclusions}

PDA with different self-polymerization degrees was successfully introduced into the aqueous phase during interfacial polymerization to improve the performance of TFC FO membranes. The surface of the membrane became compact and smooth when filled with small PDA particles while loose and rough with big PDA particles. Incorporation of DA in low-degree selfpolymerization and small PDA particles during interfacial polymerization greatly improved membrane properties in terms of perm-selectivity and structural parameter. The more hydrophilic surface, thinner, denser and highly crosslinked PA layer can provide rapid transport pathways for water media through the membrane while efficiently reject salt ions. However, selecting DA in high-degree self-polymerizations in the aqueous phase enhanced the FO membrane water permeability but sacrificed the selectivity. The optimized TFC membrane exhibited higher FO performance but lower reverse solute diffusion than most FO membranes. The improved surface hydrophilicity and smooth surface of the DA-incorporated TFC1 membrane showed enhanced antifouling properties. This study demonstrates that incorporating DA in low-degree selfpolymerization and small PDA particles during interfacial polymerization may open new venue to new high-performance antifouling FO membranes.

\section{Conflicts of interest}

There are no conflicts to declare.

\section{Acknowledgements}

The authors would like to acknowledge the financial support from CSIRO Manufacturing. Y. Wang acknowledges the collective support granted by the Graduate Student Research Innovation Project in Chong Qing (CYB15128) in 2015 and also thanks the scholarship from China Scholarship Council
(201503170336). Special thanks are given to Dr Mark Greaves and Dr Malisja de Vries from CSIRO for the SEM training and imaging in this work.

\section{References}

1 M. A. Shannon, P. W. Bohn, M. Elimelech, J. G. Georgiadis, B. J. Marinas and A. M. Mayes, Science and technology for water purification in the coming decades, Nature, 2008, 452, 301-310.

$2 \mathrm{M}$. A. Montgomery and M. Elimelech, WATER and SANITATION in Developing Countries: Including Health in the Equation, Environ. Sci. Technol., 2007, 41(1), 17-24.

3 S. Zhao, L. Zou and D. Mulcahy, Brackish water desalination by a hybrid forward osmosis-nanofiltration system using divalent draw solute, Desalination, 2012, 284, 175-181.

4 Y.-J. Choi, J.-S. Choi, H.-J. Oh, S. Lee, D. R. Yang and J. H. Kim, Toward a combined system of forward osmosis and reverse osmosis for seawater desalination, Desalination, 2009, 247, 239-246.

$5 \mathrm{~S}$. Zhao and L. Zou, Effects of working temperature on separation performance, membrane scaling and cleaning in forward osmosis desalination, Desalination, 2011, 278, 157-164.

6 J. Korenak, S. Basu, M. Balakrishnan, C. Helix-Nielsen and I. Petrinic, Forward Osmosis in Wastewater Treatment Processes, Acta Chim. Slov., 2017, 64, 83-94.

$7 \mathrm{~W}$. Xue, K. Yamamoto and T. Tobino, Membrane fouling and long-term performance of seawater-driven forward osmosis for enrichment of nutrients in treated municipal wastewater, J. Membr. Sci., 2016, 499, 555-562.

8 X. Wang, Y. Zhao, B. Yuan, Z. Wang, X. Li and Y. Ren, Comparison of biofouling mechanisms between cellulose triacetate (CTA) and thin-film composite (TFC) polyamide forward osmosis membranes in osmotic membrane bioreactors, Bioresour. Technol., 2016, 202, 50-58.

9 X. Wang, V. W. C. Chang and C. Y. Tang, Osmotic membrane bioreactor (OMBR) technology for wastewater treatment and reclamation: advances, challenges, and prospects for the future, J. Membr. Sci., 2016, 504, 113-132.

10 S. Sahebi, S. Phuntsho, J. Eun Kim, S. Hong and H. Kyong Shon, Pressure assisted fertiliser drawn osmosis process to enhance final dilution of the fertiliser draw solution beyond osmotic equilibrium, J. Membr. Sci., 2015, 481, 6372.

11 S. Phuntsho, H. K. Shon, S. Hong, S. Lee, S. Vigneswaran and J. Kandasamy, Fertiliser drawn forward osmosis desalination: the concept, performance and limitations for fertigation, Rev. Environ. Sci. Bio/Technol., 2011, 11, 147-168.

12 A. Altaee, A. Sharif, G. Zaragoza and A. F. Ismail, Evaluation of FO-RO and PRO-RO designs for power generation and seawater desalination using impaired water feeds, Desalination, 2015, 368, 27-35.

$13 \mathrm{~W}$. He, Y. Wang and M. H. Shaheed, Energy and thermodynamic analysis of power generation using a natural salinity gradient based pressure retarded osmosis process, Desalination, 2014, 350, 86-94. 
$14 \mathrm{~J}$. R. McCutcheon, R. L. McGinnis and M. Elimelech, Desalination by ammonia-carbon dioxide forward osmosis: Influence of draw and feed solution concentrations on process performance, J. Membr. Sci., 2006, 278, 114-123.

15 A. F. Faria, C. H. Liu, M. Xie, F. Perreault, L. D. Nghiem, J. Ma and M. Elimelech, Thin-film composite forward osmosis membranes functionalized with graphene oxide-silver nanocomposites for biofouling control, J. Membr. Sci., 2017, 525, 146-156.

16 L. Shen, S. Xiong and Y. Wang, Graphene oxide incorporated thin-film composite membranes for forward osmosis applications, Chem. Eng. Sci., 2016, 143, 194-205.

17 Q. Jia, Y. Xu, J. Shen, H. Yang and L. Zhou, Effects of hydrophilic solvent and oxidation resistance post surface treatment on molecular structure and forward osmosis performance of polyamide thin-film composite (TFC) membranes, Appl. Surf. Sci., 2015, 356, 1105-1116.

18 G. Han, S. Zhang, X. Li, N. Widjojo and T.-S. Chung, Thin film composite forward osmosis membranes based on polydopamine modified polysulfone substrates with enhancements in both water flux and salt rejection, Chem. Eng. Sci., 2012, 80, 219-231.

19 R. C. Ong, T.-S. Chung, J. S. de Wit and B. J. Helmer, Novel cellulose ester substrates for high performance flat-sheet thin-film composite (TFC) forward osmosis (FO) membranes, J. Membr. Sci., 2015, 473, 63-71.

20 N. Ma, J. Wei, S. Qi, Y. Zhao, Y. Gao and C. Y. Tang, Nanocomposite substrates for controlling internal concentration polarization in forward osmosis membranes, J. Membr. Sci., 2013, 441, 54-62.

21 X. Lu, L. H. Arias Chavez, S. Romero-Vargas Castrillon, J. Ma and $\mathrm{M}$. Elimelech, Influence of active layer and support layer surface structures on organic fouling propensity of thin-film composite forward osmosis membranes, Environ. Sci. Technol., 2015, 49, 1436-1444.

22 H.-R. Zuo, J.-B. Fu, G.-P. Cao, N. Hu, H. Lu, H.-Q. Liu, P.-P. Chen and J. Yu, The effects of surface-charged submicron polystyrene particles on the structure and performance of PSF forward osmosis membrane,, Appl. Surf. Sci., 2018, 436, 1181-1192.

23 H. Salehi, M. Rastgar and A. Shakeri, Anti-fouling and high water permeable forward osmosis membrane fabricated via layer by layer assembly of chitosan/graphene oxide, Appl. Surf. Sci., 2017, 413, 99-108.

24 J. R. McCutcheon and M. Elimelech, Influence of membrane support layer hydrophobicity on water flux in osmotically driven membrane processes, J. Membr. Sci., 2008, 318, 458466.

25 S. Zhao, L. Zou, C. Y. Tang and D. Mulcahy, Recent developments in forward osmosis: opportunities and challenges, J. Membr. Sci., 2012, 396, 1-21.

26 X. Zhang, J. Tian, S. Gao, Z. Zhang, F. Cui and C. Y. Tang, In situ surface modification of thin film composite forward osmosis membranes with sulfonated poly(arylene ether sulfone) for anti-fouling in emulsified oil/water separation, J. Membr. Sci., 2017, 527, 26-34.
27 S. Xiong, D. Y. Zhang, S. Mei, J. Liu, Y. S. Shi and Y. Wang, Thin film composite membranes containing intrinsic CD cavities in the selective layer, J. Membr. Sci., 2018, 551, 294-304.

$28 \mathrm{~W} . \mathrm{Xu}, \mathrm{Q}$. Chen and Q. Ge, Recent advances in forward osmosis (FO) membrane: chemical modifications on membranes for FO processes, Desalination, 2017, 419, 101116.

29 G. Han, T.-S. Chung, M. Toriida and S. Tamai, Thin-film composite forward osmosis membranes with novel hydrophilic supports for desalination, J. Membr. Sci., 2012, 423-424, 543-555.

30 Y. Wang, X. Li, C. Cheng, Y. He, J. Pan and T. Xu, Second interfacial polymerization on polyamide surface using aliphatic diamine with improved performance of TFC FO membranes, J. Membr. Sci., 2016, 498, 30-38.

31 S. Xiong, J. Zuo, Y. G. Ma, L. F. Liu, H. Wu and Y. Wang, Novel thin film composite forward osmosis membrane of enhanced water flux and anti-fouling property with $\mathrm{N}$-[3(trimethoxysilyl) propyl] ethylenediamine incorporated, $J$. Membr. Sci., 2016, 520, 400-414.

$32 \mathrm{X} . \mathrm{Li}, \mathrm{X} . \mathrm{Hu}$ and T. Cai, Construction of Hierarchical Fouling Resistance Surfaces onto Poly(vinylidene fluoride) Membranes for Combating Membrane Biofouling, Langmuir, 2017, 33, 4477-4489.

33 B. D. McCloskey, H. B. Park, H. Ju, B. W. Rowe, D. J. Miller, B. J. Chun, K. Kin and B. D. Freeman, Influence of polydopamine deposition conditions on pure water flux and foulant adhesion resistance of reverse osmosis, ultrafiltration, and microfiltration membranes, Polymer, 2010, 51, 3472-3485.

34 J. T. Arena, B. McCloskey, B. D. Freeman and J. R. McCutcheon, Surface modification of thin film composite membrane support layers with polydopamine: enabling use of reverse osmosis membranes in pressure retarded osmosis, J. Membr. Sci., 2011, 375, 55-62.

35 Z.-Y. Xi, Y.-Y. Xu, L.-P. Zhu, Y. Wang and B.-K. Zhu, A facile method of surface modification for hydrophobic polymer membranes based on the adhesive behavior of poly(DOPA) and poly(dopamine), J. Membr. Sci., 2009, 327, 244-253.

36 J. Zhao, Y. Su, X. He, X. Zhao, Y. Li, R. Zhang and Z. Jiang, Dopamine composite nanofiltration membranes prepared by self-polymerization and interfacial polymerization, $J$. Membr. Sci., 2014, 465, 41-48.

37 Y. Huang, H. Jin, H. Li, P. Yu and Y. Luo, Synthesis and characterization of a polyamide thin film composite membrane based on a polydopamine coated support layer for forward osmosis, RSC Adv., 2015, 5, 106113-106121.

38 L. Xu, J. Xu, B. Shan, X. Wang and C. Gao, Novel thin-film composite membranes via manipulating the synergistic interaction of dopamine and $m$-phenylenediamine for highly efficient forward osmosis desalination, J. Mater. Chem. A, 2017, 5, 7920-7932.

39 L.-x. Dong, X.-c. Huang, Z. Wang, Z. Yang, X.-m. Wang and C. Y. Tang, A thin-film nanocomposite nanofiltration membrane prepared on a support with in situ embedded 
zeolite nanoparticles, Sep. Purif. Technol., 2016, 166, 230239.

40 L.-x. Dong, H.-w. Yang, S.-t. Liu, X.-m. Wang and Y. F. Xie, Fabrication and anti-biofouling properties of alumina and zeolite nanoparticle embedded ultrafiltration membranes, Desalination, 2015, 365, 70-78.

41 S. Romero-Vargas Castrillón, X. Lu, D. L. Shaffer and M. Elimelech, Amine enrichment and poly(ethylene glycol) (PEG) surface modification of thin-film composite forward osmosis membranes for organic fouling control, J. Membr. Sci., 2014, 450, 331-339.

42 X. Lu, S. Romero-Vargas Castrillon, D. L. Shaffer, J. Ma and M. Elimelech, In situ surface chemical modification of thin-film composite forward osmosis membranes for enhanced organic fouling resistance, Environ. Sci. Technol., 2013, 47, 12219-12228.

43 A. Tiraferri, N. Y. Yip, A. P. Straub, S. Romero-Vargas Castrillon and $\mathrm{M}$. Elimelech, A method for the simultaneous determination of transport and structural parameters of forward osmosis membranes, J. Membr. Sci., 2013, 444, 523-538.

44 P. Lu, S. Liang, L. Qiu, Y. S. Gao and Q. Wang, Thin film nanocomposite forward osmosis membranes based on layered double hydroxide nanoparticles blended substrates, J. Membr. Sci., 2016, 504, 196-205.

45 Q. Jia, H. Han, L. Wang, B. Liu, H. Yang and J. Shen, Effects of CTAC micelles on the molecular structures and separation performance of thin-film composite (TFC) membranes in forward osmosis processes, Desalination, 2014, 340, 30-41.

46 M. Fathizadeh, A. Aroujalian and A. Raisi, Effect of lag time in interfacial polymerization on polyamide composite membrane with different hydrophilic sub layers, Desalination, 2012, 284, 32-41.

47 Z. Tan, S. Chen, X. Peng, L. Zhang and C. Gao, Polyamide membranes with nanoscale Turing structures for water purification, Science, 2018, 360, 518-521.

48 J.-H. Jiang, L.-P. Zhu, X.-L. Li, Y.-Y. Xu and B.-K. Zhu, Surface modification of PE porous membranes based on the strong adhesion of polydopamine and covalent immobilization of heparin, J. Membr. Sci., 2010, 364, 194-202.

49 N. Ma, J. Wei, R. Liao and C. Y. Tang, Zeolite-polyamide thin film nanocomposite membranes: towards enhanced performance for forward osmosis, J. Membr. Sci., 2012, 405-406, 149-157.

50 Y.-H. La, J. Diep, R. Al-Rasheed, M. Nassar, E. Idil Mouhoumed, A. Szymczyk and G. Dubois, The effect of cross-contamination in the sequential interfacial polymerization on the RO performance of polyamide bilayer membranes, J. Membr. Sci., 2014, 466, 348-356.

51 D. Emadzadeh, W. J. Lau, M. Rahbari-Sisakht, H. Ilbeygi, D. Rana, T. Matsuura and A. F. Ismail, Synthesis, modification and optimization of titanate nanotubespolyamide thin film nanocomposite (TFN) membrane for forward osmosis (FO) application, Chem. Eng. J., 2015, 281, 243-251.

52 H.-R. Zuo, G.-P. Cao, M. Wang, H.-H. Zhang, C.-C. Song, $\mathrm{X}$. Fang and T. Wang, Controlling the morphology and performance of FO membrane via adjusting the atmosphere humidity during casting procedure, Appl. Surf. Sci., 2018, 433, 945-956.

53 X.-Y. Chi, P.-Y. Zhang, X.-J. Guo and Z.-L. Xu, A novel TFC forward osmosis (FO) membrane supported by polyimide (PI) microporous nanofiber membrane,, Appl. Surf. Sci., 2018, 427, 1-9.

54 B. Khorshidi, T. Thundat, B. A. Fleck and M. Sadrzadeh, A Novel Approach Toward Fabrication of High Performance Thin Film Composite Polyamide Membranes, Sci. Rep., 2016, 6, 22069.

55 X.-L. Li, L.-P. Zhu, Y.-Y. Xu, Z. Yi and B.-K. Zhu, A novel positively charged nanofiltration membrane prepared from $N, N$-dimethylaminoethyl methacrylate by quaternization cross-linking,, J. Membr. Sci., 2011, 374, 33-42.

56 H. Zou, Y. Jin, J. Yang, H. Dai, X. Yu and J. Xu, Synthesis and characterization of thin film composite reverse osmosis membranes via novel interfacial polymerization approach, Sep. Purif. Technol., 2010, 72, 256-262.

57 Y. Wang and T. Xu, Anchoring hydrophilic polymer in substrate: an easy approach for improving the performance of TFC FO membrane, J. Membr. Sci., 2015, 476, 330-339.

58 Y. Cui, Q. Ge, X.-Y. Liu and T.-S. Chung, Novel forward osmosis process to effectively remove heavy metal ions, $J$. Membr. Sci., 2014, 467, 188-194.

59 M. Shi, Z. Wang, S. Zhao, J. Wang, P. Zhang and X. Cao, A novel pathway for high performance RO membrane: preparing active layer with decreased thickness and enhanced compactness by incorporating tannic acid into the support, J. Membr. Sci., 2018, 555, 157-168.

60 S. Zhang, F. Fu and T.-S. Chung, Substrate modifications and alcohol treatment on thin film composite membranes for osmotic power, Chem. Eng. Sci., 2013, 87, 40-50.

61 S. Lee, C. Boo, M. Elimelech and S. Hong, Comparison of fouling behavior in forward osmosis (FO) and reverse osmosis (RO), J. Membr. Sci., 2010, 365, 34-39.

62 C. J. van Oss, W. Wu. and A. Docoslis, The interfacial tensions with water and the Lewis acid-base surface tension parameters of polar organic liquids derived from their aqueous solubilities, Colloids Surf., B, 2001, 20, 87-91.

63 S. H. Eric and M. Vrijenhoeka, Menachem Elimelecha, Influence of membrane surface properties on initial rate of colloidal fouling of reverse osmosis and nanofiltration membranes, J. Membr. Sci., 2001, 115-128. 